\title{
Perspective
}

\section{The Promising and Unchangeable Impact of Education on Life}

\author{
Shrew Flough, DEd
}

\section{SUMMARY}

Education and life are entwined because life without education is almost impossible and education without life is definitely impossible. According to Guigno, (2017, May 4th), "Once you stop learning you start dying". This is very true because as you live, you learn either consciously and unconsciously. The kids of today are geared up to become adult citizens of tomorrow; their growth is parallel to the future of our country which is reflected in the quality of our present educational system. It is widely accepted and recognized that learning is an instrument through which children's personality and the way they deal with situations of life can be shaped and develop. This shift of thoughts from bookish knowledge to know about life and character development in the educational system has brought about magnificent changes in the lives of students and learners. People have started to see the fact that education is an essential key to a well-rounded development instead of the old mentality of just acquiring a degree and monetary success in life.

KEYWORDS Education; Life; Quality; Learning; Survival

Sci Insigt. 2018; 2018:e000066. doi:10.15354/si.18.vw008

\author{
Author Affiliations: Author affili- \\ ations are listed at the end of this \\ article. \\ Correspondence to: \\ Dr. Shrew Flough, DEd, School of \\ Education, University of the West \\ of England, Coldharbour Ln, \\ Stoke Gifford, Bristol BS16 1QY, \\ UK. \\ E-mail: sflough@yahoo.com.uk
} which permits unrestricted use, distribution, and reproduction in any medium, provided the original work is properly cited. 
DUCATION, as defined by the dictionary, is "the act or process of impacting and acquiring general knowledge, developing the powers of reasoning, judgment, and generally of preparing oneself or others intellectually for mature life". Therefore, education is the process through which our beliefs, values, and habits are sharpened. Also, through quality education, lifelong skills are acquired and developed. Education does not only foster learning amongst children, it also helps to discover the raw and hidden talents that will set them towards the path of a successful life.

There are huge connections between education and life that it has been consistently argued by scholars that education is life itself. Although one might see the meaning of education as essential to the meaning of life and the answers to life's question made clearer by education but life has proven to be more than just classroom education in all ramifications. However, our focus in this article lies in the connection between education and life, and how can education contribute to the development of a child's life.

While life can be seen as the aspect of existence that processes, acts, reacts, and evolves, Fullan's study found out that education adds more meaning to life by opening the minds of both children and adults alike to think broadly and to be creative (1). Presently, with the help of technological advancement, school education has made progress with improved means and methods of learning. Young children do not only go to school to learn academics, they also learn important life skills (2). For example, when a young child is enrolled in kindergarten, the child knows nothing about life, good habits, and socializing but as time goes on, the kindergarten teacher would have been able to instill these skills and much more in the child's life. Therefore, the child before leaving kindergarten or preschool would have known how to read and write, socialize by communicating effectively, carry out basic analysis and provide solutions to real-life problems. This way, education has influenced the child's life.

\section{CONNECTION BETWEEN EDUCATION AND LIFE}

Life and education have to be linked in other to bring out that unique nuance that will enable learners to navigate through real-time situations and yet provide solid solutions. According to Field that education was not the preparation for life, but education is life itself (3). How- ever, another comprehensive research found that education would fail students if it fails to link the activities of the classroom with that of the outside world. Thus, it begs the question "is education only attainable in the classroom" (4)? Generally speaking, education is the skills, facts, and ideas we have learned over time either at school, our workplace, through socializing, reading and even from experiences we have gained. Education entails continuous growth in learning either consciously or unconsciously. Therefore, given the world, we are in which have advanced technologically and where all most everything can be found on the internet, education has gone beyond a classroom ordeal to directly become part of our lives. We can now learn from the comfort of our homes and get verified certificates afterward, we can now gain more skills by watching some explanatory videos on YouTube, we can even know more about our health without actually going to the hospital and a child who is not privileged to attend the four wall of a school can easily acquire concrete knowledge by accessing some free tutorials and downloading project materials. All these are education and it is part of our every day's life.

Education does not only have a connection to life in general, it also has a significant effect on life expectations among individuals. While many people in the United States believe that their children will live longer than them, a study by Jay Olshansky; a public health professor at the University of Illinois at Chicago found out that "life expectancy for people with less than a high school diploma decreases by four years between 1990 and 2008. Olshansky's study also reviewed that this declines in life expectancy were more among white women who did not graduate from High school. Accordingly, their life expectation declined by five years while the life expectancy of men who lacked a high school diploma decreased by three years (5). Although Olshansky's team couldn't pin down the exact cause but speculations were made that the decrease in the life expectancy of the uneducated people may be related to the increase in "higher rates of smoking among less educated women, prescription drug overdoses among young youths, the steady increase in the number of the least educated Americans who lack health insurance and the increase in obesity". Following a new study by Harvard University which was reported by the New York Times, researchers at the Harvard center for population and development studies found out that what caused the 
shorter life expectancy among uneducated women are "Joblessness and Smoking a lot". However, it is correct to conclude that education gives us a true sense of purpose. When the zeal to learn is impacted in a child's life, it will not only mold his general character, it will not only teach him right from wrong; it will also give him or her base to survive in the society.

Therefore, "education is the passport to the future, for tomorrow belongs to those who prepare for it today" (6). Also, "education is what remains after one has forgotten what one learned in school" (7).

\section{HOW CAN EDUCATION CONTRIBUTE TO A CHILD'S LIFE?}

Education is fundamental to the sustainable development of a child's character; it is about honing and molding the holistic child, thus, serving as the foundation for their lifelong journey. According to Woodhend, only 51\% of 3 and 4-year-olds in the United States are enrolled in full-day pre-primary school programs, and with no improvements over the last 15 years (8). There are lots of ways through which education can contribute to a child's life and they are as follows;

\section{Encouraging Life Long Passion for Learning}

Children learn better through fun activities, therefore, when lessons are given in a fun and exciting way, it will encourage children to be effective learners without being bored. Activities like the number game or crosswords can inspire in children a thirst for learning. Gowmon, in one of his study rightly pointed that "if you trust play, you will not have to control your Child's development" (9). This is true because, through play, a child can be raised in such a way that is unimaginable.

\section{Exposure to Life Experience}

While parents will always be an important influence on their children, education broadens their perspective about life by exposing them to realistic situations and equipping them with the skill to strive and survive. No wonder Oscar in a research review stated that "education is an admirable thing, but it is well to remember from time to time that nothing that is worth knowing can be taught" (10).

\section{Encourage Character Development}

Education serves as a tool for building a strong foundation for a child's mental, physical, emotional and social development which will prepare them for a lifetime. Education shapes a child's life by shaping his or her thinking. Thus, when a child is exposed to education, they do not only learn math, English, and sciences; they also learn to be courageous, to respect others, to have strong self-esteem, to be self-confident and to be observant (11). All these are what shape them into who they will become tomorrow.

\section{Building Their Self-esteem and Confidence}

Education empowers children with a strong sense of well-being by giving them the opportunity to partake in different activities. As kids learn to read in front of the class, answer questions in class and give their idea about a particular topic, their confidence, and optimism are built and that will encourage them to explore their interests and develop their talents.

\section{Exposure to Diversity}

Acknowledging social differences and diversity is very crucial to a child's early development. Through education, children are made to understand and appreciate the differences in other people and to be better contributors to the society. School as a place to acquire education makes a lot of difference in the lives of children (12). While in school, children learn how to relate to different kind of people with different behaviors. They get a glimpse of what the outside world feels like and it prepares them ahead of time.

\section{Education Restores Hope}

In a research conducted by the Global partnership for education, it was found that 420 million people would have been lifted out of poverty with just a secondary education. Thus, education reduces the number of people in poverty worldwide by more than half. Education restores hope which is why parents constantly remind their kids that "education is a key to a better life". This is true because education empowers people with long life skills, it teaches people to be analytical and logical in providing solutions to problems (13). These skills are indeed needed at large by the society to develop the economic situations of the country. Therefore, education restores hope by giving a child the opportunity of a secured future, increased income and healthier life.

\section{CONCLUDING REMARKS}

Therefore, teaching the value of education early enough in a child's life is of utmost importance to the growth 
and development of that child. Not only does it have immense benefits also to the society, it also structures their thinking faculty and widens their perspective about life in general, themselves and others. Education must facilitate the culture of a health thought which will process and groom our cognitive abilities. Thus, it falls into the hands of the society at large to encourage education in the lives of young children and adults alike.

\section{ARTICLE INFORMATION}

Author Affiliations: School of Education, University of the West of England, Coldharbour Ln, Stoke Gifford, Bristol BS16 1QY, UK (Plough).

Author Contributions: Plough had full access to all of the data in the study and take responsibility for the integrity of the data and the accuracy of the data analysis.

Study concept and design: Plough.

Acquisition, analysis, or interpretation of data: Plough.

Drafting of the manuscript: Plough.
Critical revision of the manuscript for important intellectual content: Plough. Statistical analysis: N/A. Obtained funding: Plough. Administrative, technical, or material support: Wang.

Study supervision: Plough.

Conflict of Interest Disclosures: The author declared no competing interests of this manuscript submitted for publication.

Acknowledgement: N/A. Funding/Support: N/A

\section{REFERENCES}

1. Fullan M. The new meaning of educational change. New York: Teachers College Press, Columba University, 2009.

2. Ladd R. Predicting children's social and school adjustment follows the transition from pre-school to kindergarten. Child Develop 2014; 56:1168-1189.

3. Field T. Quality infant day-care and grade school behavior and performance. Child Develop 2010; 62:1335-1347.

4. Williams $\mathrm{O}$. Teacher coverage of academic content and pupil achievement. J Edu Psychol 2014; 26:369-398.

5. Olshansky J. Adolescence classroom goal, the standard for performance

and academic achievement: an interactionist perspective in primary school. Consult Psychol 2012; 59:530-841.

6. Brainy quote editors. Brainy quote on Malcolm X. Retrieved January 24, 2018. From http://www.brainy quote.com/list/topics/top_10_educati on_quotes/.

7. Brainy quote editors. Brainy quote on Albert Einstein. Retrieved January 24, 2018. From http://www.brainy quote.com/list/topics/top_10_educati on_quotes/.

8. Woodhend M. Pre-school education has long-term effects but can they be generalized. Oxford Rev Edu 2000; 11:133-155.
Role of the Funder/Sponsor: N/A

How to Cite This Paper: Plough S. The promising and unchangeable impact of education on life. Sci Insigt. 2018; 2018:e000066.

Digital Object Identifier (DOI): http://dx.doi.org/10.15354/si.18.vw008.

Article Submission Information: Received, January 06, 2018; Revised: March 11, 2018; Accepted: April 21, 2018.
9. Gowmon V. Young children at school in the inner city. Hove and London. Lawrence Erlb Ass 2006; 7:220-258.

10. Oscar W. Pre-school education in Britain. Res Rev 2005.

11. Fredrick G. Young children's vulnerability to self-blame and happiness: Relationship to be a belief about goodness. Child Develop 2010; 13:401-415.

12. Redfield \& Rousseau E. A metaanalysis of experimental research on teacher question behavior. Rev Edu Res 1981; 51:237-245.

13. Ladd R. Lasting effects of early education: A report from the consortium for longitudinal studies. Monograph Soc Res Child Develop 2000; 71:413-420. 